\title{
Teachers' Aides Working in Secondary School Settings: Preparedness and Professional Learning
}

\author{
Dianne Gibson ${ }^{1}$, Louise Paatsch ${ }^{1}$, Dianne Toe $^{1}$, Muriel Wells ${ }^{1} \&$ Shaun Rawolle ${ }^{1}$ \\ ${ }^{1}$ Faculty of Arts and Education, Deakin University, Geelong, Australia \\ Correspondence: Dianne Gibson, Faculty of Arts and Education, Deakin University, Geelong, Vic, 3220, \\ Australia. Tel: 61-428-86-7479. E-mail: dgibson@deakin.edu.au
}

Received: June 11, 2015

Accepted: June 18, 2015 Online Published: August 11, 2015

doi:10.5539/jel.v4n3p71

URL: http://dx.doi.org/10.5539/jel.v4n3p71

\begin{abstract}
In Victoria, Australia teachers' aides (TAs) are employed to provide support to students with disabilities in accessing their education. The role of the TAs varies within and across school settings. Drawing from the findings of a quantitative study, the purpose of this paper is to develop an understanding of teachers' aides' perceptions of their preparedness to perform 18 student-related tasks within the state secondary school setting in Victoria, Australia. In all, 163 participants completed the on-line questionnaire. The results of the study showed that that in general TAs perceive there are tasks relevant to their roles in supporting students with disabilities; and there are tasks that are not applicable to that role. The TAs in this study considered that they had training that enabled them to effectively perform the listed student related tasks to support students with disabilities in the secondary school environment.
\end{abstract}

Keywords: teachers' aides, secondary schools, preparedness, professional learning

\section{Introduction}

In Victoria, Australia, teachers' aides (TAs) are employed to perform a myriad of tasks in supporting students with disabilities in the school setting. However questions have been raised as to the appropriateness and preparation of TAs when performing selected tasks in mainstream secondary schools. The purpose of this paper is to develop an understanding of TAs perceptions of their preparedness in performing selected student related tasks when supporting students with disabilities in inclusive secondary school settings. The research outlined in this paper presents the outcome of a study undertaken in mainstream state secondary schools in Victoria, Australia.

In Australia, like many countries in the world, schools have a duty to include students with disabilities into regular classroom settings and to provide supplementary services and additional support to make these settings effective (French, 2003). Following the assertion in the Warnock Report (United Kingdom) that "one in five": students would experience learning difficulties at some point in time, the employment of teachers' aides has increased substantially across many regions such as the United States, Canada, the United Kingdom, Scandinavia, and Australia (Department of Education and Training, 2006; Warnock, 1978). Moreover the Australian Senate, in its inquiry into the education of students with disabilities, stated that "teachers' aides have become so closely identified with integrated learning that it is hard to see how inclusive education would function without them" (The Senate, 2002, s. 1.25). However, it is unclear how well prepared and skilled TAs are in carrying out this critical role. In Victoria, Australia, the Department of Education and Training (DET) (2015) describe the role of teachers' aides as including the following tasks (1) demonstrating, supervising and participating in activities which enhance the physical, social, emotional and intellectual development of children in schools and preschool centres; (2) assisting children with intellectual, physical and behavioural difficulties with their academic studies and (3) assisting children individually to learn social skills (Department of Education and Training, 2015). Teachers' aides are generally employed from funding provided to schools based on a funding format that provides additional funding to schools to provide supplementary resources for students with disabilities. Teachers' aides in Victoria do not require training to be employed. This paper draws on research that directly addresses this gap by focussing on teacher aides' perceptions of their preparedness. The argument made in this paper is that debates about the adequacy of preparation of TAs should also be informed by research on TAs' own perceptions. In the research that underpins this argument, the data reveal that a number of researchers (e.g., 
Angelides, Constantinou, \& Leigh, 2009; Mansaray, 2006; Webster, Blatchford, Bassett, Brown, Martin, \& Russell, 2011) suggest that TAs are unprepared for their role in supporting students with disabilities in the through a lack of training or lack of clarity in defining their support role. However there is a dearth of information regarding the TAs perceptions of their role and the training they have performed to address the array of student related tasks inherent in their role. By researching the TAs perceptions the study gives agency and relevance to the TAs own voices and experiences in providing an understanding of, and direction for, better informed utilization of TAs as support personnel for students with disabilities within the secondary school environment.

Teachers' aides are increasingly being deployed as the main support mechanism for students with disabilities in schools, both internationally and within Australia (Giangreco \& Doyle, 2002; Groom, 2006; Inclusive Education Network, 2006). This has led to an increase in the number of TAs employed in schools. The impact of this increase has created issues for many school communities both in terms of financial allocations and program delivery (Dempsey, 2008; Farkas \& Duffett, 2012; Inclusive Education Network, 2006; Pearson, 2012; Picus, 2000). While TAs appear to be the preferred method for supporting students with disabilities in the classroom, researchers have questioned the use of untrained or under-skilled TAs in supporting students with the highest need in schools (Giangreco \& Broer, 2005). In Australia, including the State of Victoria, the Senate inquiry (2002) into the education of students with disabilities reported that "most teachers' aides have no specialist training in teaching for disabilities, and a great many may lack even basic training", and recommended that "within a reasonable period, all teachers' aides working with students with disabilities should be qualified in special education from an accredited teacher aide training course, and that this should be a condition of additional Commonwealth funding for disability education" (The Senate, 2002, p. 7). This finding was further supported by the Victorian Auditor General's Report (2012) who noted that "a decade on, the issue of unqualified aides remains unresolved" (p. 29), and that this is compounded by the broad role definitions assigned to TAs . Furthermore it has impacted the understanding of the role of the TA and has provided a wide scope for interpretation of the varied tasks required to be performed by TAs by the school administration, teachers, and the TAs themselves (Liston, Nevin, \& Malian, 2009; Ministerial Advisory Committee: Students with Disabilities, 2005; The Senate, 2002).

It is evident in the research and within Australian national policy documents that the role of the TA is diverse (Liston et al., 2009; Ministerial Advisory Committee: Students with Disabilities, 2005; The Senate, 2002). Such a role encompasses supporting students' with disabilities across a range of educational, physical and social needs. In particular, national policies state that TAs can provide physical support by facilitating access to classrooms with strategies for enabling alternative means of participation if necessary (Commonwealth of Australia, 2006). Furthermore, TAs can provide educational support to enable students with disabilities to be given the opportunity to participate in the general education curriculum (Commonwealth of Australia, 2006). For many TAs, supporting students with disabilities involves taking on responsibility for their learning and can involve providing emotional support to students through a range of areas including social support, welfare support and career advice (Angelides et al., 2009; Giangreco \& Doyle, 2002; Inclusive Education Network, 2006).

Takala (2007), in her research into the work of TAs in special and mainstream education in Finland, identified that the support needs of children with disabilities mainly occur in five areas: (1) communication, (2) social skills, (3) curriculum access, (4) personal care, and (5) mobility. Takala also suggests that the main goal of the TAs' work is to assist and support the student during the learning process. While researchers have argued that the role of the TA needs to be defined, the impact of the expectations of a range of stakeholders, including the students with disabilities, parents, teaching staff and the school community, makes this a complex task (French, 2003; The Senate, 2002). In the secondary school setting each group of stakeholders has a purpose for the employment of TAs, whether it be the parents to provide social support and/or academic support; the students for social, physical and/or academic support; the teachers for academic support; or the school community for inclusive education support (Brown \& Devecchi, 2013; Chopra, 2009; Chopra \& French, 2004; Egilson \& Traustadottir, 2009; French, 2003; Logan, 2006).

A range of studies which investigated the role of the TA, teachers were largely positive about the contribution of TAs in the classroom. Overall, TAs were perceived as supporting the teacher by supporting the students (Blatchford, Russell, Bassett, Brown, \& Martin, 2007; Forlin, Keen, \& Barrett, 2008; Mansaray, 2006). In contrast, Giangreco and Doyle (2002) reported that the assignment of TAs may be an expedient support solution for students with disabilities. If so, their deployment may be both unfair to the TAs and questionably effective for the students they support. They stated that whether TA supports are or are not effective "depends on what they are intended to accomplish" (p. 3) This is further emphasised by Webster et al. (2011) following the largest 
study of school support staff (the DISS project) in the UK who questioned the current model of TA deployment and the finding that TAs can have a negative impact on students' academic progress. Although this finding is relevant to the UK model of TA deployment, in Victoria, Australia TAs are employed to facilitate learning and not to teach the curriculum. However, despite the DET role description TAs can be given this responsibility through misunderstanding or misuse in the classroom. Similarly, concerns about the role and duties of the TA, the extent and in what circumstances they should be used, and what degree and type of training they should receive have also been reported by other researchers (Chopra et al., 2004; Egilson \& Traustadottir, 2009; French, 2003; Giangreco \& Broer, 2005; Gibson, Paatsch, \& Toe, (n.d., in print); Webster et al., 2010; Whitburn, 2013). TAs are required to perform a variety of tasks when working in a school supporting students with disabilities, however, little is known about the frequency with which TAs perform common student related tasks, their level of preparedness to perform those tasks, and if their own views on their need for training in those tasks. The gap that exists in current research is an explicit focus on TAs' perceptions of their effectiveness.

This purpose of the study that informs this paper was to explore TAs' perceptions of their preparedness for supporting students with disabilities across a number of common student related tasks in state secondary schools in Victoria. The study also examined TAs training needs related to these tasks. Specifically, this study sought to investigate the following three aims: (1) the frequency of specific student-related tasks carried out by TAs, (2) the level of preparedness of teachers' aides to perform particular student-related tasks, and (3) the level of training needed to perform particular tasks with students with disabilities.

This paper draws on some of the results of this study to argue that it is relevant to explore TAs perceptions of their preparedness and training to perform student related tasks. By providing TAs with a voice a better understanding of the role TAs perform in supporting student with disabilities in the mainstream secondary school environment. The results of this study show that in general TAs perceive there are student related tasks relevant to their roles in supporting students with disabilities; and there are tasks that are not applicable to that role. The TAs in this study considered that they had training that enabled them to effectively perform the listed student related tasks to support students with disabilities in the secondary school environment. The results of this study may be used to inform schools as to the student related tasks TAs perceive to be part of their role. The results may also assist in guiding the formation and definition of job descriptions especially in light of the question "can one person effectively do all that?"

\section{Research Design}

Data for this research were collected using an anonymous on-line questionnaire. One hundred and sixty-three participants completed the questionnaire. The questionnaire sought to investigate teachers' aides' educational background, specific training undertaken as part of their role, the frequency of tasks carried out by TAs, and to identify further professional learning needs.

\section{Data Generation}

Three hundred and seventy-four principals from 299 secondary school (Years 7-12) campuses in the state of Victoria, Australia were invited to approach their teachers' aides to participate in the study. Principals were asked to forward an invitational email to the TAs in their school who supported secondary students with disabilities. There were no criteria which excluded any teachers' aides from participating in this research. It was important to ensure that a broad range of opinions and experiences were gathered regarding TAs' perceptions of their own professional learning needs when working with students with disabilities in the state secondary school system.

The questionnaire was developed on the basis of a review of the literature. In particular, the work of Giangreco (2002) and Carter (2010) informed the development of many of the items included in the questionnaire relating to TAs' knowledge and skills, the specific tasks that TAs are often reported to perform daily, and specific needs for further professional learning in supporting students with disabilities. The anonymous questionnaire consisted of 28 items that included tick-the-box, nominal, and open-ended questions. Items one to seven gathered demographic data about the participants including gender, age group, length of time working as a TA, the number of schools the TAs had worked in, the number of hours per fortnight working as a TA, and their own level of education. Items eight to 13 explored TAs professional learning prior to commencing work as a TA. Specifically, these items asked participants to indicate whether they had received any accredited training or any induction materials, and to describe their work experience as a TA. Items 14 to 21 sought to explore TAs weekly work schedules including the school setting they work in, the number of students with disabilities and the number of teachers that they work with, the number of academic subjects they work in, and the year levels from which the students with disabilities are enrolled in. Item 22 invited participants to rate their level of knowledge 
in 11 disability categories including autism, visual and hearing impairment, cognitive impairment, or physical disability. Items 23 to 26 investigated teacher aides' level of knowledge and skill in carrying out many of the tasks related to work as a TA. For example, participants were invited to rate their own level of knowledge and skills related to various disability categories, and 31 specific work-related activities associated with their role as a TA in a state secondary school setting (i.e., implementing Individual Learning Plans, ethical practices, liaising with classroom teachers etc.). The final two items invited participants to add any further comments and indicate whether they were willing to participate in a focus group.

The anonymous on-line questionnaire responses were collected using Survey Monkey across a six week period. The number of on-line questionnaires returned was 166 with each participant being delegated a Teachers' Aide (TA) number code ranging from TA1 to TA166 based on their questionnaire submission date. However, 3 of the questionnaires were not included in the final analysis because two questionnaires were repeat submissions (TA84 and TA140) and one (TA86) was because the respondent came from a Special School and this was outside the scope of this research. This resulted in an overall return number of 163.

\section{Results}

\subsection{Participants}

One hundred and sixty-three participants completed the on-line questionnaire. Responses from the first 7 items from the questionnaire showed that the majority of the participants were female (94.4\%) and were predominately in the 50-55+ age category (68.3\%).

Results showed that $67.5 \%$ of participants had completed post school training at Certificate, Diploma, Undergraduate or Postgraduate level. The majority of participants (33.1\%) had completed Certificate level education. Participants noted that their certificate level training was in an assortment of study areas including nursing, hairdressing, typesetting, horticulture and art. Nine of the participants noted that they were currently studying either a Certificate or undergraduate degree. Five of these participants noted that their studies were in Education.

The results showed that all participants $(\mathrm{N}=163)$ had been working as $\mathrm{TAs}$ for between two months and 32 years $(M=9.9$ years $)$. The number of schools the participants $(N=163)$ had worked in ranged from 1 to 8 , with the average being between 2 and $3(\mathrm{M}=2.3)$ schools. Three of the participants (TA21, TA149 and TA154) noted they had worked in both secondary and primary schools, and four noted they worked across multiple campuses of the same school (TA13, TA38, TA88 and TA128). Eighteen of the participants (11\%) indicated they had worked as a teacher. The average time as a teacher was 12 years but the majority of replies were in the range of 14 years or less.

Participants reported working with up to $10+$ students with disabilities in a typical week. The greater proportion of TAs (38.7\%) worked with 4 to 6 students in a typical week. The results showed that participants worked with 5 to 8 different teachers $(60.8 \%)$ across 5 to 8 different subjects $(63.2 \%)$ during a typical week.

The majority of responses indicated that TAs typically work with students with disabilities in /or mostly in general classroom settings $(68.0 \%)$. The majority of participants worked evenly between working in groups or one-on-one with the students they support (93.1\%). A smaller number of participants responded that they worked only in groups or only one-on-one $(6.9 \%)$. A minority of participants indicated they worked mostly or always in special education/withdrawal classes (5.7\%).

\subsection{Frequency of Performing Student Related Tasks}

The questionnaire included an item related to the frequency of performing student related tasks. The item had two sections. The first section of item 23 invited participants to indicate how often they carried out particular activities in their work as TA. Specifically, participants were asked to indicate the frequency in which they typically perform each of the 17 listed activities ranging from daily to annually. The 8 point scale in this item included the following: daily, weekly, fortnightly, monthly, termly, annually, never or not applicable (NA). Tasks that participants chose as NA may not be applicable to their understanding of the role they perform, for example "write lesson plans"; or they may not be applicable to the students they are currently supporting at the school, for example "working with students with refugee backgrounds". This item on the questionnaire also included an open-ended section whereby participants were asked to indicate any other activities, and how often, they undertook in their role as a TA. The second section of item 23 was an open-ended question which asked the participants to indicate any other activities they undertook in their role as TAs, and how often they undertook these activities. 
Table 1. Frequency of activities undertaken by participants in their work as TAs $(n=161)$

\begin{tabular}{|c|c|c|c|c|c|c|c|}
\hline Activities & Daily & Weekly & Fortnightly & Monthly & Termly & Annually & $\begin{array}{c}\text { Never/NA } \\
(\text { Note 1) }\end{array}$ \\
\hline $\begin{array}{l}\text { Assist single } \\
\text { students in class }\end{array}$ & $87.1 \%$ & $10.3 \%$ & $1.3 \%$ & $0.6 \%$ & $0.0 \%$ & $0.6 \%$ & $1.2 \%$ \\
\hline Liaise with teachers & $80.8 \%$ & $12.8 \%$ & $1.9 \%$ & $3.2 \%$ & $1.3 \%$ & $0.6 \%$ & $0.6 \%$ \\
\hline $\begin{array}{l}\text { Work with multiple } \\
\text { students in a class }\end{array}$ & $72.4 \%$ & $21.8 \%$ & $1.9 \%$ & $0.6 \%$ & $0.0 \%$ & $0.6 \%$ & $2.5 \%$ \\
\hline $\begin{array}{l}\text { Facilitate social } \\
\text { relationships } \\
\text { amongst students }\end{array}$ & $47.7 \%$ & $13.1 \%$ & $4.6 \%$ & $1.3 \%$ & $6.5 \%$ & $2.0 \%$ & $24.9 \%$ \\
\hline $\begin{array}{l}\text { Modify a student's } \\
\text { work program }\end{array}$ & $46.8 \%$ & $28.8 \%$ & $2.6 \%$ & $1.9 \%$ & $0.6 \%$ & $0.6 \%$ & $18.8 \%$ \\
\hline Liaise with parents & $9.9 \%$ & $24.5 \%$ & $8.6 \%$ & $12.6 \%$ & $24.5 \%$ & $2.0 \%$ & $18.5 \%$ \\
\hline $\begin{array}{l}\text { Attend PSG (Note 2) } \\
\text { meetings }\end{array}$ & $1.9 \%$ & $0.0 \%$ & $3.8 \%$ & $8.3 \%$ & $64.7 \%$ & $8.3 \%$ & $13.5 \%$ \\
\hline $\begin{array}{l}\text { Attend training } \\
\text { sessions }\end{array}$ & $1.3 \%$ & $1.3 \%$ & $2.0 \%$ & $9.2 \%$ & $42.5 \%$ & $33.3 \%$ & $11.1 \%$ \\
\hline Yard duty & $8.1 \%$ & $12.8 \%$ & $0.7 \%$ & $0.7 \%$ & $0.0 \%$ & $0.7 \%$ & $77.7 \%$ \\
\hline Write lesson plans & $5.6 \%$ & $6.3 \%$ & $3.5 \%$ & $2.8 \%$ & $2.8 \%$ & $2.1 \%$ & $77.1 \%$ \\
\hline $\begin{array}{l}\text { Provide therapy } \\
\text { assistance }\end{array}$ & $6.8 \%$ & $10.2 \%$ & $0.7 \%$ & $3.4 \%$ & $2.0 \%$ & $2.0 \%$ & $75.5 \%$ \\
\hline Write reports & $2.7 \%$ & $2.7 \%$ & $1.3 \%$ & $3.3 \%$ & $16.0 \%$ & $5.3 \%$ & $70.0 \%$ \\
\hline $\begin{array}{l}\text { Administer student } \\
\text { assessments }\end{array}$ & $3.4 \%$ & $3.4 \%$ & $4.1 \%$ & $2.0 \%$ & $14.3 \%$ & $4.8 \%$ & $69.4 \%$ \\
\hline $\begin{array}{l}\text { Provide health care } \\
\text { assistance }\end{array}$ & $14.8 \%$ & $14.8 \%$ & $4.0 \%$ & $6.7 \%$ & $4.0 \%$ & $3.4 \%$ & $52.3 \%$ \\
\hline $\begin{array}{l}\text { Implement } \\
\text { behaviour } \\
\text { management } \\
\text { programs }\end{array}$ & $18.7 \%$ & $10.7 \%$ & $4.7 \%$ & $4.0 \%$ & $8.0 \%$ & $5.3 \%$ & $49.4 \%$ \\
\hline $\begin{array}{l}\text { Prepare instructional } \\
\text { materials }\end{array}$ & $11.3 \%$ & $28.5 \%$ & $7.3 \%$ & $6.6 \%$ & $4.0 \%$ & $2.6 \%$ & $39.7 \%$ \\
\hline $\begin{array}{l}\text { Complete } \\
\text { administrative } \\
\text { paperwork }\end{array}$ & $26.5 \%$ & $10.6 \%$ & $4.6 \%$ & $5.3 \%$ & $14.6 \%$ & $2.0 \%$ & $37.7 \%$ \\
\hline
\end{tabular}

Table 1 shows the majority of responses per activity and the frequency in which the participants undertook the activity. The majority of participants $(\mathrm{n}=161)$ indicated that five of the activities listed were undertaken on a daily basis including assist single students in class $(87.1 \%)$, liaise with teachers $(80.8 \%)$, work with multiple students in class (72.4\%), facilitate social relationships amongst students $(47.7 \%)$ and modify a student's work program (46.8\%). There was one activity that was undertaken equally most frequently on a weekly and termly basis being "liaising with parents" $(25.4 \%)$ and two activities were undertaken most frequently on a termly basis which were "attending PSG meetings" (64.7\%) and "attend training sessions" (42.5\%).

The participants indicated there were tasks they "never' performed or the task was "not applicable" (NA) to their role as a TA. The figures in the frequency section of Table 1 represents the total of the "never" and the NA tasks. In total there were 9 tasks that the majority of participants indicated "never" and NA; see Table 1 for item-level data. The participants may have responded "never" or "Not Applicable" to the these activities because they are not currently performing these tasks with the students they support, which means they may have, or could, 
perform these tasks depending on the needs of the students. Similarly the participants may have responded "never" because the activity has not currently been allocated to them or because of the different expectations of the schools they currently work in.

In the open-ended section of item 23 of the questionnaire, the participants were asked to indicate any other activities they undertook in their role as TAs. They were also asked to indicate how often they undertook these activities. Forty nine of the 163 participants (30\%) responded to this section of the questionnaire. Twenty-nine of the 49 participants (59\%) noted that they photocopied teachers' work regularly although the frequency varied. Six participants noted that they undertook administration work, for example, TA136 wrote: "office reception daily" and TA114 wrote: "supervise the Silent Planning Room (2 periods per week), accompany on excursion weekly with my PE class, assist in the administration area perhaps 2-3 times per week".

Participants also wrote they worked in first aid (3), in the library (4), corrected students work (3), toileted students (3), participated in excursions (2) and yard duty (playground duty) (2) as explained by TA94:

I've ticked yard duty as I am required to spend 10-15 minutes daily opening rooms so Year 8 students can get their books from lockers prior to the commencement of the day.

While the frequency varied, the other tasks noted by participants included organizing speech therapy, proof reading reports, running the breakfast program, assisting in the canteen (when required), and meal assistance. Some participants noted that they performed more than one role in their school, for example TA166 wrote:

I have 2 roles within the school yr 7 Ass [Year 7 assistant] team leader and time as aide. My time is primarily spent working modifying etc but photo copying and lesson planning is quite common.

\subsection{Preparedness to Perform Student Related Tasks}

The questionnaire included two items related to TAs' preparedness to work with students with disabilities upon commencing work as a TA. Item 11 asked TAs to indicate whether they had received any induction information upon commencing work as a TA. $67.7 \%$ of participants indicated that they had been given induction information upon employment.

Item 12 invited participants to indicate whether they had received any information in the following 5 areas: (1) individual student's needs, (2) school policies and practices, (3) personal safety and care practices, (4) implementation of individual programs and (5) key legislation.

In regard to student related tasks $84.8 \%$ of participants indicated they had received information regarding individual student needs; $78.8 \%$ had received information regarding school policies and practices, $67.6 \%$ had been given information regarding personal safety and care policies, $56.3 \%$ were given information regarding implementation of individual programs and 39.1\% had received information regarding key legislation.

There was an open ended "other please specify" section for further clarification regarding the information given to TAs prior to starting work with students with disabilities. Nineteen participants responded. TA63 noted they were: "verbally told information necessary to work with different students" with TA154 noting that "I was given general and specific information on all student disabilities and strategies on how to best work with the student."

There were two items in the questionnaire that related to TAs' knowledge and skills, and their level of preparedness to perform particular student-related tasks. Item 22 invited participants to rate their level of knowledge and skills related to 12 disability categories including learning disability, Autism, speech or language impairment, emotional disturbance, cognitive disability, physical impairment, multiple disabilities, hearing impairment, visual impairment, traumatic brain injury, Deaf-Blindness or other health impairment. Participants were asked to rate according to the 4-point Likert scale including "very low", "low", "moderate" or "high". Results showed that the majority of participants $(\mathrm{M}=52.4 \%)$ nominated moderate for their level of knowledge and skill across 10 of the 12 listed disabilities. Of the other two categories Deaf-blindness and traumatic brain injury the majority of participants $(\mathrm{M}=37 \%)$ nominated a low level of knowledge and skill.

Item 24 from the questionnaire asked participants to indicate how prepared they felt they were to effectively perform 18 student related tasks that they may be required to carry out. Participants were asked to use a 5 point Likert scale of unprepared, a little prepared, moderately prepared, very prepared and NA (not applicable) to indicate their preparedness to perform the listed tasks effectively. Table 2 presents the results of this item. 
Table 2. Participants' preparedness to effectively perform activities $(n=159)$

\begin{tabular}{|c|c|c|c|c|c|}
\hline Tasks & Unprepared & $\begin{array}{c}\text { A little } \\
\text { prepared }\end{array}$ & $\begin{array}{l}\text { Moderately } \\
\text { prepared }\end{array}$ & $\begin{array}{l}\text { Very } \\
\text { prepared }\end{array}$ & NA \\
\hline Liaise with teachers & $1.3 \%$ & $0.6 \%$ & $9.0 \%$ & $89.0 \%$ & $0.0 \%$ \\
\hline $\begin{array}{l}\text { Assist single students in } \\
\text { class }\end{array}$ & $0.0 \%$ & $1.3 \%$ & $12.2 \%$ & $86.5 \%$ & $0.6 \%$ \\
\hline $\begin{array}{l}\text { Work with multiple } \\
\text { students in a class }\end{array}$ & $0.0 \%$ & $0.6 \%$ & $22.2 \%$ & $76.1 \%$ & $0.6 \%$ \\
\hline Attend PSG meetings & $1.3 \%$ & $1.9 \%$ & $18.1 \%$ & $72.3 \%$ & $7.1 \%$ \\
\hline Liaise with parents & $1.3 \%$ & $4.6 \%$ & $18.3 \%$ & $64.7 \%$ & $11.8 \%$ \\
\hline $\begin{array}{l}\text { Modify a student's work } \\
\text { program }\end{array}$ & $0.0 \%$ & $8.4 \%$ & $29.7 \%$ & $51.6 \%$ & $10.3 \%$ \\
\hline $\begin{array}{l}\text { Using appropriate } \\
\text { technology to assist } \\
\text { student learning }\end{array}$ & $3.9 \%$ & $6.5 \%$ & $36.8 \%$ & $49.7 \%$ & $3.2 \%$ \\
\hline $\begin{array}{l}\text { Complete administrative } \\
\text { paperwork }\end{array}$ & $2.7 \%$ & $8.0 \%$ & $18.0 \%$ & $46.7 \%$ & $24.7 \%$ \\
\hline $\begin{array}{l}\text { Facilitate social } \\
\text { relationships amongst } \\
\text { students }\end{array}$ & $4.1 \%$ & $6.8 \%$ & $25.7 \%$ & $45.9 \%$ & $18.2 \%$ \\
\hline $\begin{array}{l}\text { Prepare instructional } \\
\text { materials }\end{array}$ & $2.0 \%$ & $10.5 \%$ & $23.0 \%$ & $37.5 \%$ & $27.0 \%$ \\
\hline $\begin{array}{l}\text { Provide health care } \\
\text { assistance }\end{array}$ & $3.3 \%$ & $16.0 \%$ & $18.0 \%$ & $35.3 \%$ & $28.7 \%$ \\
\hline $\begin{array}{l}\text { Implement behaviour } \\
\text { management programs }\end{array}$ & $2.6 \%$ & $13.6 \%$ & $26.0 \%$ & $33.8 \%$ & $26.6 \%$ \\
\hline $\begin{array}{l}\text { Working with students } \\
\text { from diverse cultural and } \\
\text { religious backgrounds }\end{array}$ & $7.2 \%$ & $13.1 \%$ & $29.4 \%$ & $32.0 \%$ & $19.6 \%$ \\
\hline Write lesson plans & $8.7 \%$ & $8.7 \%$ & $15.4 \%$ & $17.4 \%$ & $50.3 \%$ \\
\hline Write reports & $8.1 \%$ & $8.8 \%$ & $13.5 \%$ & $25.0 \%$ & $48.6 \%$ \\
\hline $\begin{array}{l}\text { Administer student } \\
\text { assessments }\end{array}$ & $6.0 \%$ & $9.4 \%$ & $22.1 \%$ & $19.5 \%$ & $44.3 \%$ \\
\hline Provide therapy assistance & $10.9 \%$ & $11.6 \%$ & $17.7 \%$ & $19.7 \%$ & $40.8 \%$ \\
\hline $\begin{array}{l}\text { Working with students } \\
\text { who have refuge } \\
\text { backgrounds }\end{array}$ & $11.9 \%$ & $15.9 \%$ & $25.2 \%$ & $21.2 \%$ & $26.5 \%$ \\
\hline
\end{tabular}

The majority of TAs $(67 \%)$ indicated that they were "very prepared" $(45.7 \%)$ or "moderately" $(21.0 \%)$ to perform the 18 listed student related tasks. A minority of participants (12.1\%) indicated they were "a little prepared" $(8.0 \%)$ or "unprepared" $(4.1 \%)$ to perform the 18 listed student related tasks.

Of the 18 listed tasks the majority of participants' responses (50.4\%) indicated that they were very prepared to effectively perform 13 of the tasks. Of the remaining 5 student related tasks the majority of responding participants $(\mathrm{m}=46.0 \%)$ indicated that these tasks were NA (not applicable) to their role as TAs (see Table 2).

\subsection{Training}

The questionnaire included four items related to training. Item 8 invited participants to indicate any accredited education and training they had completed specifically related to their role as a TA. There were 6 categories for participants to select from. The categories included postgraduate degree, undergraduate degree, Vocational and 
Educational Training (VET), training days, traineeship or no accredited training. The participants were able to select more than one category. For example TA 40, TA63 and TA80 indicated they had completed a traineeship and attended training days; TA75 and TA163 had completed a VET course and training days; and TA 154 indicated they had completed a postgraduate course and had attended training days. Results showed that the majority of participants (77.5\%) indicated that they had participated in training including postgraduate and undergraduate studies, VET courses, traineeships and training days relevant to their roles as TAs. The majority of participants $(70.4 \%)$ had participated in training days. $22.5 \%$ of participants indicated they had no accredited training specific to their role as a TA.

Item 9 asked participants to describe any personal or work experience relevant to their work as a TA. One hundred and five participants responded to the open ended question which asked the participants to describe any personal or work experience and its relevance to their work as a TA. The data was scrutinized for emerging themes. There were four main themes which emerged:

(1) Educational training or school based work.

There were 22 responses included in this theme. For example TA29 wrote:

I trained and achieved my Numeracy and Literacy Certificates at (a named school). I have learnt more on the job and attending PDs whenever I am able to go. I have worked with many students with a range of disabilities and I continue to learn.

(2) Being a parent and/or relation of a person with a disability.

There were 26 participants whose responses were included in this group. For example, TA101 noted: "my brother has cerebral palsy". TA 47 noted:

I am currently studying teaching. I have volunteered for Special Olympics and have an autistic nephew and a step brother and sister with alphamonosidosis.

(3) Experiences gained through volunteering or working at a school.

Nineteen participants responded with comments related to this theme. For example, TA34 wrote:

I was teaching a Prep/One class when the new Integration Policy came in, around 1984 I think it was. I ended up with a boy with cerebral palsy in my room that could not even sit up, go to the toilet, or talk-and I was expected to cope with NO assistance! It was very challenging, and I must admit I resented that little boy's presence. But it was also rewarding, and may be part of the reason why I love working in Integration now.

(4) Community service.

Twenty-six of the participants wrote of their experiences from working or volunteering in a community setting. For example, TA64 wrote:

I worked for Human Services - Intellectual Disability before working in a school for many years.

Item 10 asked participants to indicate how they rate the level of importance of training and professional development in performing their role as a TA who works with students with disabilities across a 5 point Likert scale of not important, slightly important, important, quite important and very important. Results showed that the majority (61.7\%) of participants responded that training and professional development in performing their role as a TA who works with students with disabilities was very important; $20.4 \%$ indicated it was quite important; and the remaining $17.9 \%$ responded that it was important/slightly important. No participant indicated that training was not important.

Item 26 asked participants to indicate whether they had had training in the 18 student related tasks from item 24 . Participants were also asked to rate their need for additional training in the 18 listed tasks. Table 3 presents the results for this item.

Table 3. Participants' training and professional learning needs related to activities undertaken in their work as TAs $(\mathrm{n}=158)$

\begin{tabular}{llllll}
\hline \multicolumn{1}{c}{ Tasks } & $\begin{array}{c}\text { Yes I have had } \\
\text { training }\end{array}$ & No need & $\begin{array}{c}\text { Some } \\
\text { need }\end{array}$ & $\begin{array}{c}\text { Moderate } \\
\text { need }\end{array}$ & $\begin{array}{c}\text { Substantial } \\
\text { need }\end{array}$ \\
\hline Assist single students in class & $\mathbf{6 9 . 7 \%}$ & $22.6 \%$ & $16.1 \%$ & $7.7 \%$ & $4.5 \%$ \\
Work with multiple students in & $\mathbf{6 2 . 1 \%}$ & $23.5 \%$ & $20.3 \%$ & $7.2 \%$ & $3.3 \%$ \\
\hline
\end{tabular}




\begin{tabular}{|c|c|c|c|c|c|}
\hline \multicolumn{6}{|l|}{ a class } \\
\hline Attend PSG meetings & $45.1 \%$ & $37.3 \%$ & $16.3 \%$ & $7.8 \%$ & $3.3 \%$ \\
\hline $\begin{array}{l}\text { Modify a student's work } \\
\text { program }\end{array}$ & $44.1 \%$ & $22.4 \%$ & $28.3 \%$ & $13.2 \%$ & $5.9 \%$ \\
\hline Write reports & $20.8 \%$ & $49.3 \%$ & $13.2 \%$ & $10.4 \%$ & $11.1 \%$ \\
\hline Liaise with teachers & $37.7 \%$ & $49.0 \%$ & $13.9 \%$ & $5.3 \%$ & $4.0 \%$ \\
\hline Write lesson plans & $16.8 \%$ & $47.7 \%$ & $20.8 \%$ & $9.4 \%$ & $10.1 \%$ \\
\hline Administer student assessments & $19.5 \%$ & $43.6 \%$ & $21.5 \%$ & $9.4 \%$ & $11.4 \%$ \\
\hline Liaise with parents & $34.0 \%$ & $41.8 \%$ & $20.3 \%$ & $7.8 \%$ & $3.9 \%$ \\
\hline $\begin{array}{l}\text { Complete administrative } \\
\text { paperwork }\end{array}$ & $31.5 \%$ & $37.0 \%$ & $24.7 \%$ & $9.6 \%$ & $6.2 \%$ \\
\hline Prepare instructional materials & $28.1 \%$ & $35.3 \%$ & $26.8 \%$ & $11.8 \%$ & $5.9 \%$ \\
\hline Provide therapy assistance & $17.3 \%$ & $35.3 \%$ & $28.0 \%$ & $10.0 \%$ & $13.3 \%$ \\
\hline Provide health care assistance & $32.2 \%$ & $32.9 \%$ & $28.9 \%$ & $11.8 \%$ & $5.3 \%$ \\
\hline $\begin{array}{l}\text { Working with students who } \\
\text { have refuge backgrounds }\end{array}$ & $17.2 \%$ & $30.3 \%$ & $26.9 \%$ & $17.2 \%$ & $12.4 \%$ \\
\hline $\begin{array}{l}\text { Using appropriate technology to } \\
\text { assist student learning }\end{array}$ & $32.0 \%$ & $17.3 \%$ & $35.3 \%$ & $18.0 \%$ & $8.7 \%$ \\
\hline $\begin{array}{l}\text { Facilitate social relationships } \\
\text { amongst students }\end{array}$ & $28.6 \%$ & $28.6 \%$ & $34.7 \%$ & $10.9 \%$ & $6.8 \%$ \\
\hline $\begin{array}{l}\text { Working with students from } \\
\text { diverse cultural and religious } \\
\text { backgrounds }\end{array}$ & $19.0 \%$ & $27.2 \%$ & $34.7 \%$ & $13.6 \%$ & $11.6 \%$ \\
\hline $\begin{array}{l}\text { Implement behaviour } \\
\text { management programs }\end{array}$ & $28.9 \%$ & $24.2 \%$ & $32.9 \%$ & $9.4 \%$ & $12.8 \%$ \\
\hline AVERAGE & $32.5 \%$ & $33.7 \%$ & $24.7 \%$ & $10.6 \%$ & $7.8 \%$ \\
\hline
\end{tabular}

\subsection{Participants' Results "Training Experience"}

The results show that the majority of participants (66.2\%) indicated that they had "had training" or that they had "no need" for training across the 18 listed student related tasks. TAs considered that they had sufficient knowledge and skills to be able to perform the tasks allocated to them. Whether through training, professional learning or experience "on the job", TAs indicated that they felt they were prepared to perform the indicated tasks with understanding. Some of the tasks had a lower indicator score in the "yes, I have had training" tally. This may be because the TAs did not need the training or professional development to address this issue at the time of completing the questionnaire. For example "provide health care assistance" may not be relevant to the students they have, or are currently supporting. Similarly TAs may not have training in the listed task as it was not in their job description or they did not consider it was part of their role, hence training had not been necessary at the time of the response. For example "using appropriate technology to assist student learning", TAs may consider this is not a part of their role, rather they consider it to be the teachers' role.

In responding "no need" for training TAs may have been indicating that they had had adequate training in the selected item or they may have been indicating that the selected task was not relevant to their current role. As shown in Figure 9 there were only four tasks that TAs indicated fell below the "training needed" tally on the table. The result implies that TAs have a broad level of understanding of work related items and tasks that may be assigned to them in secondary schools in Victoria.

\subsection{Training Needs}

Item 26 also asked participants to rate their level of need for training on a 4 point Likert scale of no need, some need, moderate need and substantial need. Results showed that teacher' aides indicated that between 30\%-50\% of participants had "no need" for training and professional learning in 11 of the listed tasks (see Table 3 for 
item-level data). From the remaining 7 listed tasks six of the tasks scored between 20\%-29\% for "no need" for training and professional learning. One listed task, "using appropriate technology to assist student learning", scored $17.3 \%$. There were no tasks scored below $17 \%$.

In the "some need" for training section of this question there were no responses above $40 \%$. Four listed tasks had a response rate of between 30\%-39\% from the participants; see Table 3 for item-level data. The 20\%-29\% response rate included ten tasks from the list. There were 4 tasks where participants' responded to having "some need" for training and professional learning below 19\%. They included "attend PSG meetings" (16.3\%); "assist single students in class" (16.1\%); "liaise with teachers" (13.9\%); and "write reports" (13.2\%).

The participants' responses to "moderate need" for training across the 18 listed tasks scored below $20 \%$. Nine of the listed tasks were rated between $10 \%-20 \%$. The highest task participants rated as "moderate need" for training and professional learning was "using appropriate technology to assist student learning" (18.0\%). The remaining 9 listed tasks rated below $10 \%$.

Results indicated that less than $15 \%$ of participants had "substantial need" for training and professional learning in the 18 listed tasks. The highest response rate was $13.3 \%$ of participants who indicated they had "substantial need" for training and professional learning in "providing therapy assistance", followed by "implement behaviour management programs" (12.8\%). In all, seven items rated between 10-15\%. The remaining 11 listed tasks rated below $10 \%$ with 5 of these listed tasks being rated below $5 \%$.

Item 27 provided an opportunity for participants to write any comments regarding TAs' roles, training and/or professional learning. Fifty-five participants wrote additional comments. There were some general themes that emerged:

(1) Participants discussed the need for training and professional learning as a prerequisite to being employed as a TA. For example TA 61 and TA 153 suggested that the role should become a "qualified position".

While agreeing with the need for training TA103 wrote that "integration training is not long or intense enough", however as TA39 asserted "as the roles vary sometimes on a daily basis it is difficult to ascertain what training is required as many students have very different needs and abilities". TA158 offered a different perspective when writing:

aides' roles vary from school to school, some schools have a higher expectation, others just want you in the class-nothing more.

(2) Participants commented on the difficulty of providing training and professional learning to adequately address the many duties a TA performs. For example TA145 explained:

teachers' aides work in many varied areas. It would be very difficult to provide a training course to train aides as every situation is different...For each area you work in, you need specific training for that area, and then it needs to be more than just one day PD's. Training for aides is continual and complex.

TA149 wrote:

aides roles have increased, individual student needs vary dramatically one size doesn't fit all. Legislation is constantly changing, we need to be upskilled in all these areas along with teachers. Team work is the key but shared information is paramount to a successful cohesive working environment for all parties.

Similarly TA104 wrote:

It is important for subject teachers to take ownership for all students in the class and for them to instruct aides on what they what the child to achieve and work with the aide to modify and adapt work to suit.

(3) Participants commented on the value of workplace training and professional learning. For example TA57 wrote:

the main training and professional learning takes place in the workplace as all schools have different needs and students with varied disabilities. Over the past 25 yrs I have worked with many students with many different needs and now run weekly meetings with the aides at our school to discuss and share strategies and knowledge. There is little appropriate PL available for working in Secondary schools. Common sense and empathy are the main requirements for successful aides. A knowledge of the individual student's disability and their needs is essential.

(4) A further theme was working with students with disabilities in the secondary school. For example TA9 wrote: 
I think there is a great need for PD's related to secondary school education, strategies for assisting adolescence. Good PD's (with good presenters) related to various disabilities and behaviour management are always useful. The need for behavioural management strategies is becoming more urgent as there are many students with problems in this area $\&$ once they hit secondary school their abilities to cope becomes increasingly difficult both on an academic and social level.

TA129 summed up their secondary school working experience by writing:

when working in the Primary sector where you are present in the class constantly and with just one teacher it is very important to be a bit of a chameleon taking on the "tone" and style of the classroom teacher. When working in the Secondary arena where multiple classroom teachers are involved, acting as an advocate when necessary, gently reminding the teacher that it is the "student" who is responsible for their work and not the aide. The aide is a facilitator for the students' education and is not responsible for educating the student ... That's the teachers' job. In a perfect world the student should be given as much of the teachers time as any other student in the class.

\section{Discussion}

The findings show that TAs report working with a number of students within multiple contexts in a typical week. TAs typically work with students with disabilities one-on-one or in groups, mostly in the general classroom setting. TAs also report working with a variety of teachers across a number of subjects and year levels. Researchers have been reported that TAs need knowledge to understand their roles within the school environment (Dymond, Renzaglia, Gilson, \& Slagor, 2007; Etscheidt, 2005; Giangreco, Yuan, McKenzie, Cameron, \& Fialka, 2005; Griffin-Shirley \& Matlock, 2004; Howard \& Ford, 2007; Idol, 2006; Lewis, 2004; Pearce \& Forlin, 2005; The Senate, 2002). This knowledge relates to work related items and student related tasks. While reports indicate that knowledge of work related items are important (e.g., Carter et al., 2009) this study investigated the tasks directly related to working with students with disabilities in the secondary school. The discussion is presented under 3 subheadings (1) Frequency; (2) Preparedness; and (3) Training.

\subsection{Frequency}

This study found that there are tasks which TAs typically perform regularly. TAs reported that there were 5 tasks they performed on a daily basis. In general, these tasks related to providing classroom assistance to the students, for example "assist single students in class", and "liaise with teachers". These results concur with an Australian study by Howard and Ford (2007), which investigated TAs' perceptions of their roles and responsibilities in 31 secondary schools in Adelaide, and found that TAs reported that they may spend up to $50 \%$ of their working day providing direct instruction to students.

One task "complete administrative paper work" was performed daily by $26.5 \%$ of teachers' aides, however the majority of TAs (37.7\%) responded in the NA/never category for this item. This indicates that there is an inconsistency in the expectation to, and performance of, this task by TAs within different schools. It may also be interpreted that TAs are being given tasks that should fall within the responsibility of certified teachers and the school administration. By allocating these tasks to TAs schools may be crossing professional lines; the outcome could have legal implications for the school (Etscheidt, 2005).

TAs reported that they prepared instructional materials on a weekly basis.

"Liaise with parents" was rated equally between weekly and termly. "Attend PSG" meetings also rated as termly, which is the format where TAs are likely to be liaising with parents. This may be because PSG meetings are required to be held once a term as part of the Victorian Government's Programs for Students with Disabilities funding scheme (DEECD, 2013). TAs indicated that they were often invited to attend these meetings to provide information to parents on their child's progress and in setting Individual Education Plan goals. Anecdotally, in secondary schools parents tend to be less involved with the daily running of the school and therefore there is less chance for incidental liaising with parents. This could account for the difference in TAs' responses.

The study found that there were 9 tasks which the majority of TAs reported were not applicable or that they never performed in their role in supporting students with disabilities in secondary schools. Four of the tasks were seen as the responsibility of the teacher and included "yard duty", "rite lesson plans", "write reports" and "administer student assessments". Despite this finding, there was a minority of TAs who reported performing these tasks. Again schools may be putting themselves at risk of legal challenges by allocating tasks to uncertified personnel which fall outside their legal responsibility.

The other five tasks related to the specific needs of individual students and may be in the NA/never category because the TAs see the tasks as being not part of their role, or as being not part of their current role. For 
example provide therapy assistance may be considered by some TAs as not part of their role in supporting the students with disabilities where this service is provided by professionals who are attached to the school to deliver this service; or the school does not have students (at the time of completing the questionnaire) who need this type of support.

In general the TAs in this study had similar responses to the frequency of student related tasks performed in their roles across a typical year. This implies that there is a level of consistency in the performance of tasks by TAs across the role for which they are employed. This concurs with the findings of Gibson et al. (n.d., in press) who reported that the perceptions of the roles of TAs by teachers and TAs were similar in the areas of inclusion, student support and classroom management. In the current study the results show that TAs assume a wide variety of tasks during a typical school week. The most frequently performed tasks relate to working directly with students within the general classroom.

TAs reported the "other" roles they perform within the school which not only supplement their employment but also to "fill the gap" to allowing for the smooth running of the school. These tasks were varied and showed flexibility within the structure of the role to perform ancillary tasks which included performing first aid, working in the library, yard duty, running the breakfast program and assisting in the canteen. The frequency of performance of these tasks varied, some tasks were performed regularly and others were performed as the need arose.

\subsection{Preparedness}

Preparedness is connected to the awareness of knowledge, skills and understanding involved in performing the tasks related to the role of being a TA. It is concerned with the training and professional learning of TAs relevant to their roles as TAs as well as the day-to-day aspects of TA deployment.

One area which provided information to prepare TAs in performing their roles was induction information. Balshaw (2010) reports that induction is a significant factor in developing preparedness, skills and confidence. The majority of TAs reported receiving induction information regarding individual student's needs $(84.8 \%)$, and implementation of individual programs (56.3\%). TAs considered this information was relevant to their role as a TA supporting students with disabilities and their understanding of the individual needs of the students they were assigned to.

TAs generally reported being very prepared to perform 13 of the 18 tasks they were frequently assigned. In contrast this result is contrary to that of Carter et al. (2009) who reported from their findings that in general TAs reported feeling just adequately prepared to assume the tasks they were frequently assigned. From their results, Carter et al. (2009) were unable to ascertain whether TAs felt more competent in tasks they regularly performed or whether TAs were assigned tasks they were more prepared to perform. This study found that the majority of TAs $(66.9 \%)$ felt they were "very prepared" or "moderately prepared" to perform the task assigned to them. Similar to Carter et al. (2009) the results did not specify whether this was because TAs were assigned to tasks they were more prepared to perform or whether they were competent in tasks they regularly performed, however as the average time working as a TA was nearly 10 years $(\mathrm{M}=9.9$ years) it could be inferred that on-the-job experience provided the knowledge and skills to enable TAs to rate themselves as more than adequate in performing these tasks. Additionally eighteen of the participants (11\%) indicated they had also worked as a qualified teacher, implying they have a high level of preparedness to perform their role.

The remaining 5 tasks $(\mathrm{M}=42.1 \%)$ were considered to be not applicable to the role of the TAs responding to this study. These tasks were considered to be tasks TAs should not perform, for example "write lesson plans", or are tasks which may not be within the role of the TA when responding to the questionnaire, for example "provide therapy assistance". Despite these tasks being considered not applicable to the majority of TAs, over $20 \%$ of TAs $(\mathrm{M}=20.6 \%)$ indicated they were very prepared to perform these tasks. This indicates that while TAs considered these tasks were not applicable to their role, a minority of TAs considered they had the ability to perform these tasks if required. This result may indicate that TAs had previously had training to be able to perform these tasks, for example nursing training for providing therapy assistance. The results may also indicate that TAs are being given tasks that are clearly in the teachers' domain, for example writing lesson plans, and questions the role of the teacher in allocating or expecting these tasks to be performed by TAs.

There were several tasks where a percentage of TAs reported being very prepared to perform whilst other TAs considered the tasks to be not applicable to their role in supporting students with disabilities in the secondary school. For example a number of TAs $(26.5 \%)$ indicated that they "completed administrative paperwork" on a daily basis, of these TAs the majority indicated that they were very prepared to perform this task (46.7\%). 
Equally there was $24.7 \%$ of TAs who responded that this task was not applicable to their role when nominating their level of preparedness to perform the task. This is further illustrated by the results pertaining to the task of "prepare instructional materials" where $28.5 \%$ of TAs reported performing this task on a weekly basis. While the majority of TAs $(37.5 \%)$ reported they were very prepared to prepare instructional materials, $27 \%$ of TAs responded that this task was not applicable to their role. Another task which had results which were divisive was "implement behaviour management programs". While the majority of TAs (26.6\%) indicated that the task was not applicable to their role, other TAs acknowledged this as part of their role by responding that they were very prepared to perform the task (33.8\%). Where some TAs considered it to be the job of the teacher, other TAs considered it was "part of their job" (TA137) to ensure that the students they support understood appropriate classroom behaviour. From their study Howard and Ford (2007) reported that TAs were expected to be responsible for the behaviour management of the students they support, however this study found that while this was the view of some participants, others did not perceive this to be part of their role in the classroom. This further indicates that the tasks allocated to TAs may be reactive in addressing the needs of the students with disabilities in the classroom where TAs roles are manipulated to address different issues that arise in supporting these students. It may be interpreted that schools consider the needs of students with disabilities can be adequately addressed by TAs rather than by fully qualified teachers or specialist staff. However it may also be seen as exploitation by schools in allocating such responsibilities to undertrained, lowly paid TAs.

A further outcome of the study shows that there are different needs within different schools when supporting students with disabilities. For example, $25.2 \%$ of TAs responded they were moderately prepared to work with students with refugee backgrounds, $26.5 \%$ responded this was not applicable when indicating their preparedness to perform this task. TA30 in commenting on the NA response to "working with students who have refugee backgrounds" stated: "as we are a small school we do not have any students from refugee backgrounds at the moment, it would be good to learn about these so that we can assist if we do get any." This illustrates the differing understandings and expectations of the role of the TA in schools. It also indicates the need for schools to address the needs of the differing clientele peculiar to schools across the state of Victoria rather than just assigning TAs to fill the gap in addressing the diverse needs of students within different school cohorts.

\subsection{Training}

A number of researchers (e.g. Giangreco and Broer (2005), Carter et al. (2009)) report the need for training for TAs, implicit in the notion is that TAs have little or no training. However the results of this study indicate that the majority of TAs had participated in post Year 12 training, in particular Certificate courses. The courses were not necessarily related to their role as a TA, however, the knowledge and skills learnt within the post school studies may be transferable to working with students with disabilities in the school environment. For example, a TA who had studied nursing could have an understanding of the physical and medical issues which may impact the student. Similarly, a hairdresser may have the skills to facilitate social relationships amongst students because of working with a broad range of people understanding and listening to their needs. The majority of TAs (77.5\%) also indicated that they had participated in training, including postgraduate and undergraduate studies, VET courses, traineeships and training days relevant to their roles as TAs. The majority of participants (70.4\%) had participated in single training days. The outcome, as shown by this study, is that TAs believe that they have accessed relevant training or consider they have no need for training in 14 of the 18 listed student related tasks. However, despite the TAs perception of their training levels, there is a general questioning from within the educational community of their ability to perform the myriad of tasks assigned to them (Gibson et al., n.d., in press). This may be resolved by TAs participating in a regime of formal training that could provide the TA with a clear understanding of their role. This understanding may then be extended to other members of the school community to establish unequivocal role definitions for TAs within schools. Similarly by providing TAs with clearly defined roles, all members of the school community would be able to work towards accessing and understanding the explicit roles assigned to TAs within their schools.

While $22.5 \%$ of participants indicated they had no accredited training specific to their role as a TA, the results of this study show that the majority of TAs had experience with people with disabilities in a variety of settings including work experience, personal experience and volunteering. These experiences provided the TAs with knowledge and skills which could be transferred to their role in working with students with disabilities in the school environment. This study found that TAs considered these experiences provided a level of training needed to perform their role in supporting students with disabilities. Despite the outcomes of this study regarding the knowledge and skills TAs have from training or experiences, there is a hiatus between how TAs see themselves, and how external evaluators see them. For example, the Victorian Auditor General's Report (2012) asserts that the issue of unqualified aides is unresolved, however this study found that TAs considered formal training and 
experience provided them with the knowledge and skills to consider themselves to be very prepared to perform their support roles. As an outcome the implicit confidence of TAs to address the issues which impact students with disabilities in the regular classroom may, as challenged, adversely affect the students they are there to support.

The majority of TAs (52.5\%) reported that they had a moderate level of knowledge and skill across 10 of the 12 listed disabilities. Of the other two categories Deaf-blindness and traumatic brain injury the majority of participants $(\mathrm{M}=37 \%)$ nominated a low level of knowledge and skill. It may be inferred that this is due to the low numbers of students with these disabilities enrolled in regular secondary schools. Carter, O'Rourke et al. (2009) suggest that the extent to which the disability factors affect the TAs role can have clear implications for the training needs of TAs. Therefore it could be asserted that there should be different training competencies required to address the diversity of needs of the individual student. For example a qualified TA trained in and assigned to support a student with cerebral palsy may not have the equivalent training to support a student with a severe behaviour disorder. The implications for the TA is that they only support particular students within their skill set or that they do further training, which can impact the TAs' time and commitment, but also the timetabling and financial allocation of the school. Similarly if TAs were involved in more comprehensive training focussing on areas including behaviour, learning styles and needs, and communication their understanding of the idiosyncrasies particular to individual student's disabilities may be lacking.

TAs indicated they had moderate/substantial need for training or professional learning in some areas related to their roles as a TA. For example, $26.7 \%$ of TAs reported needing additional training in using appropriate technology to assist student learning, and $18.4 \%$ for implement behaviour management program. This result may imply that TAs may not have sought training in these areas. Equally this result may indicate that TAs are relying on on-the-job training to improve their skills in these areas. It may also indicate that training or professional learning is not available, for example there is no training/courses that addresses these issues; or it is not accessible to these participants. For example funding, time release or distance may inhibit the TAs' accessibility to any relevant training. Over $25 \%$ of TAs indicated they needed additional training in working with students who have refuge backgrounds $(29.6 \%)$ and working with students from diverse cultural and religious backgrounds $(25.2 \%)$. This indicates that a number of TAs consider they do not have adequate knowledge of these areas when addressing the individual needs of these students. This may be indicative of the increasing role of the TAs in being allocated support roles for these students. It may also indicate that TAs may not have knowledge in these areas as their schools have few, if any, refuge or culturally diverse students enrolled, as was explained by TA30 regarding their limited knowledge in this area.

The Senate (2002) recommended that all TAs working with students with disabilities should be qualified in special education from an accredited TA training course. The results of this study show that TAs believe that they gain adequate knowledge and skills though formal, informal, on-the-job training, professional learning and personal experience from a range of sources. TAs report that they feel very prepared to perform the assigned tasks to support the students with disabilities to whom they are assigned. Two issues have emerged from this study. First, stakeholders should address the teacher-type responsibilities being allocated to TAs rather than placing the blame for a lack of knowledge and skill on TAs limited training. Giangreco, Smith and Pinckney (2006, p. 215) reported that inappropriate practices by teachers' aides such as making instructional decisions without always having teacher or special educator oversight, does not occur "because of any wrong doing", rather it is an indicator of the problems in special education or general education. They posit that this would not be corrected by merely providing teachers' aides with more training, but that the result would simply perpetuate the practice of limiting access of students with disabilities to instruction from certified teachers and special educators. TAs should not be expected to be the expert in all fields of curriculum but should be capable of providing the physical, social and educational support to students with disabilities to facilitate learning and be an active member of the school community. A clear definition of the role and its boundaries would support TAs, and schools to maximise the benefits of TA support for students with disabilities. Second, the mismatch between the TAs perceptions of their training needs and the findings from independent evaluations (Pearson, 2012) and other researchers (Inclusive Education Network, 2006; The Senate, 2002) needs further investigation. TA's feel well-prepared, and this is encouraging, but do they have training and education needs that they are unaware of?

\section{Conclusion}

"The essence of successful deployment of teaching assistants lies in understanding the nature of support they can provide. This includes support for the pupil, teacher, curriculum and school" (Department for Education and Skills, 2000, p. 8). This study has established that TAs considered there are tasks which they perceive as relevant 
to their role in supporting students with disabilities; and there are tasks that are not applicable to that role. The tasks perceived to be relevant to their roles coincide with a general understanding within the national policy of the teachers' aides' role of providing support to students with disabilities within the regular classroom. However it is also evident that there are issues that need to be addressed regarding TAs being given tasks that should fall within the responsibility of certified teachers and the school administration that could have legal implications for the school. While a number of researchers (e.g., Giangreco and Broer (2005), Carter, O'Rourke et al. (2009) question TAs training, TAs in this study consider that, in regard to the tasks relevant to their role, training provided the knowledge and skills to prepare them to effectively perform the listed student related tasks to support students with disabilities in the secondary school environment.

TAs stressed that the role of TAs was diverse and constant learning was a vital part of performing the role effectively. However whether the TAs' perception of their support role coincides with the perception of others remains moot. As discussed there are listed tasks pertaining to the role where the TAs disagree, if then TAs can't agree on their role this then extrapolates out to the broader community of teachers, students and parents who have a vested interest in the support role of TAs in the secondary school setting. Similarly there may also be implications for policy makers regarding the discrepancy of tasks allocated to TAs in their support roles.

The results of this study into the perceptions of TAs' preparedness in performing their roles may be useful in providing knowledge to understand the diversity of the roles and the impact of working with students with different ranges and levels of disability in schools. The results may be used to inform training regimes within the school and for outsourcing program designers to enable them to design programs relevant to the needs of the TAs. The results may also be used to inform policy makers of the role of the TA in the school, as the TA perceives it to be, to further develop and enhance the support role of the TA in working with students in the secondary school setting. Similarly the results may be used to inform policy makers of tasks that TAs should not be required to perform whether through a lack of certified training or within the bounds of legal and ethical principles.

If as French (2003, p. 9) proposes, that "program integrity and quality are based on the quality and preparation of those who deliver services to students". The outcomes of this study may enable a better understanding of the support services provided by TAs in assisting students with disabilities to access their all aspects of learning.

\section{References}

Angelides, P., Constantinou, C., \& Leigh, J. (2009). The role of paraprofessionals in developing inclusive education in Cyprus. European Journal of Special Needs Education, 24(1), 75-89. http://10.1080/08856250802596741

Balshaw, M. (2010). Looking for some different answers about teaching assistants. European Journal of Special Needs Education, 25(4), 337-338. http://10.1080/08856257.2010.513534

Blatchford, P., Russell, A., Bassett, P., Brown, P., \& Martin, C. (2007). The role and effects of teaching assistants in English primary schools (Years 4 to 6) 2000-2003. Results from the Class Size and Pupil-Adult Ratios (CSPAR) KS2 Project. British Educational Research Journal, 33(1), 5-26. http://10.1080/01411920601104292

Brown, J., \& Devecchi, C. (2013). The impact of training on teaching assistants' professional development: Opportunities and future strategies. Professional Development in Education, 39(3), 369-386. http://10.1080/19415257.2012.762720

Carter, E. (2010). Paraprofessional Survey. Department of Rehabilitation Psychology and Special Education, Wisconsin.

Carter, E., O'Rourke, L., Sisco, L., \& Pelsue, D. (2009). Knowledge, responsibilities, and training needs of paraprofessionals in elementary and secondary schools. Remedial and Special Education, 30(6), 344-359. http://10.1177/0741932508324399

Chopra, R. (2009). What do parents need to know about paraeducators? Exceptional Parent, 39(9), 22-23.

Chopra, R., \& French, N. (2004). Paraeducator relationships with parents of students with significant disabilities. Remedial and Special Education, 25, 240-251.

Chopra, R., Sandoval-Lucero, E., Aragon, L., Abernal, C., Debalderas, H., \& Carroll, D. (2004). The paraprofessional role of connector. Remedial and Special Education, 25, 219-231. 
Commonwealth of Australia. (2006). Disability Standards for Education 2005. Retrieved May 23, 2010, from www.ag.gov.au/www/adg/agd.nsf/Page/Humanrightsandantidiscrimimation_DisabilitiesStandardsforEducat ion

DEECD. (2013). Programs for students with disabilities guidelines 2014.

Dempsey, I. (2008). National reporting and students with a disability in the United States and Australia. Australasian Journal of Special Education, 26(1/2), 16-31. http://10.1080/1030011020260103

Department for Education and Skills. (2000). Working with teaching assistants: A good practice guide. Retrieved October 28, 2010, from http://nationalstrategies.standards.dcsf.gov.uk/node/85096

Department of Education and Training. (2006). A summary review of inclusive education policies and practices. Retrieved June 28, 2010, from http://knowledge.education.vic.gov.au/sites/knowledgebank/knowledgebank/Lists/Case\%20Studies/Attach ments/884/KBVO2-0045-19.pdf

Department of Education and Training. (2015). Victorian Skills Gateway. Retrieved from http://www.education.vic.gov.au/victorianskillsgateway/Students/Pages/OccupationSearchDescription.aspx ?type $=$ occupation $\&$ keyword $=\&$ searchid $=911$

Dymond, S., Renzaglia, A., Gilson, C., \& Slagor, M. (2007). Defining access to the general curriculum for high school students with significant cognitive disabilities. Research and Practice for Persons with Severe Disabilities, 32(1), 1-15.

Egilson, S., \& Traustadottir, R. (2009). Assistance to pupils with physical disabilities in regular schools: Promoting inclusion or creating dependency. Eurpoean Journal of Special Needs Education, 24(1), 21-36. http://10.1080/08856250802596766

Etscheidt, S. (2005). Paraprofessional services for students with disabilities: A legal analysis of issues. Research and Practice for Persons with Severe Disabilities, 30(2), 60-80.

Farkas, S., \& Duffett, A. (2012). How Americans would slim down public education. Washington D. C.

Forlin, C., Keen, M., \& Barrett, E. (2008). The concerns of mainstream teachers: Coping with inclusivity in an Australian Context. Journal of Disability, Development and Education, 55, 251-264. http://10.1080/10349120802268396

French, N. (2003). Paraeducators in special education programs. Focus on Exceptional Children, 36(2), 1-16.

Giangreco, M. (2002). Project EVOLVE. Centre on Disability and Community Inclusion, Burlington.

Giangreco, M., \& Broer, S. (2005). Questionable utilization of paraprofessionals in inclusive schools: Are we addressing symptoms or causes? Focus on Autism and Other Developmental Disabilities, 20, 10-26. http://dx.doi.org/10.1177/10883576050200010201

Giangreco, M., \& Doyle, M. (2002). Students with disabilities and paraprofessional supports: Benefits, balances and band-aids. Focus on Exceptional Children, 34(7), 1-12.

Giangreco, M., Smith, C., \& Pinckney, E. (2006). Addressing the paraprofessional dilemma in an inclusive school: A program description. Research \& Practice for Persons with Severe Disabilities, 31(3), 215-229.

Giangreco, M., Yuan, S., McKenzie, B., Cameron, P., \& Fialka, J. (2005). "Be careful what you wish for..." Five reasons to be concerned about the assignment of individual paraprofessionals. Teaching Exceptional Children, 37(5), 28-34.

Gibson, D., Paatsch, L., \& Toe, D. (n.d., in press). An analysis of the role of teachers' aides in a state secondary school, as perceived by the teaching staff and the teachers' aides. Australasian Journal of Special Education.

Griffin-Shirley, N., \& Matlock, D. (2004). Paraprofessionals speak out: A survey. Rehabilitation Education for Blindness and Visual Impairment, 36(3), 127-136. http://dx.doi.org/10.3200/REVU.36.3.127-136

Groom, B. (2006). Building relationships for learning: The developing role of the teaching assistant. Support for Learning, 21, 199-203. http://10.1111/j.1467-9604.2006.00432.x

Howard, R., \& Ford, J. (2007). The roles and responsibilities of teacher aides supporting students with special needs in secondary school settings. Australian Journal of Special Education, 31(1), 25-43. http://10.1080/10300110701268461 
Idol, L. (2006). Towards inclusion of special education students in general education. Remedial and Special Education, 27(2), 77-94. http://dx.doi.org/10.1177/07419325060270020601

Inclusive Education Network. (2006). Inclusive Education in Victoria: It's about will, skill and capacity.

Lewis, K. (2004). Instructional aides: Colleagues or cultural brokers? The School Community Journal, 14(1), 91-112.

Liston, A., Nevin, A., \& Malian, I. (2009). What do paraeducators in inclusive classrooms say about their work? Analysis of national survey data and follow-up interviews in California. Teaching Exceptional Children Plus, 5(5), Article 1. Retrieved from http://escholarship.bc.edu/education/tecplus/vol5/iss5/art1

Logan, A. (2006). The role of the special needs assistant supporting pupils with special educational needs in Irish mainstream primary schools. Support for Learning, 21(2), 92-99. http://10.1111/j.1467-9604.2006.00410.x

Mansaray, A. (2006). Liminality and in/exclusion: Exploring the work of teaching assistants. Pedagogy, Culture \& Society, 14(2), 171-187. http://10.1080/146813600738335

Ministerial Advisory Committee: Students with Disabilities. (2005). Professional development for school service officers in South Australia: Government of South Australia.

Pearce, M., \& Forlin, C. (2005). Challenges and potential solutions for enabling inclusion in secondary school. Australasian Journal of Special Education, 29(2), 93-105. http://10.2260/1030-0112.29.2.0261

Pearson, D. (2012). Programs for students with special learning needs. In Auditor-General (Ed.), Victorian Government.

Picus, L. (2000). How schools allocate and use their resources. Retrieved May 10, 2014, from http://www.eric.ed.gov/contentdelivery/servlet/ERICServlet?accno=ED452578

Takala, M. (2007). The work of classroom assistants in special and mainstream education in Finland. British Journal of Special Education, 34(1), 50-57. http://dx.doi.org/10.1111/j.1467-8578.2007.00453.x

The Senate. (2002). Employment, workplace relations and education references committee: Education of students with disabilities. Canberra: Commonwealth of Australia.

Warnock, H. M. (1978). Special Eductional Needs: Report of the Committee of Enquiry into the Education of Handicapped Children and Young People. London Her Majesty's Stationery Office. Retrieved from http://www.educationengland.org.uk/documents/warnock/warnock1978.html.

Webster, R., Blatchford, P., Bassett, P., Brown, P., Martin, C., \& Russell, A. (2010). Double standards and first principles: Framing teaching assistant support for pupils with special educational needs. European Journal of Special Needs Education, 25, 319-336. http:// 10.1080/08856257.2010.513533

Webster, R., Blatchford, P., Bassett, P., Brown, P., Martin, C., \& Russell, A. (2011). The wider pedagogical role of teaching assistants. School Leadership and Management, 31(1), 3-20. http://10.1080/13632434.2010.540562

Whitburn, B. (2013). The dissection of paraprofessional support in inclusive education: You're in mainstream with a chaperone. Australasian Journal of Special Education, 37, 147-161. http://10.1017/jse.2013.12

\section{Notes}

Note 1. Not Applicable

Note 2. Program Support Group

\section{Copyrights}

Copyright for this article is retained by the author(s), with first publication rights granted to the journal.

This is an open-access article distributed under the terms and conditions of the Creative Commons Attribution license (http://creativecommons.org/licenses/by/3.0/). 